\title{
Selective antifungal action of crude extracts of Cassia fistula L.: A preliminary study on Candida and Aspergillus species
}

\author{
Panda, S. K., ${ }^{*}$ Brahma, S. and Dutta, S. K. ** \\ Post Graduate Dept. of Zoology, North Orissa University, Baripada -757003, India. \\ E-mail: * sujogyapanda@gmail.com; ** sk_dutta@yahoo.com \\ Received 20 June 2009; received in revised form 10 October 2009; accepted 30 October 2009
}

\begin{abstract}
Preliminary studies on the phytochemicals and extracts of petroleum ether, chloroform, ethanol, methanol and aqueous of Cassia fistula leaves were examined for antifungal activity using agar cup and broth dilution methods. Although all five extracts showed promising antifungal activity against Candida albicans (12.6 mm), C. krusei (13.3 mm), C. parapsilosis $(14.0 \mathrm{~mm})$, and $C$. tropicalis $(14.3 \mathrm{~mm})$, yet maximum activity was observed in methanol extract followed by ethanol and aqueous extracts. Petroleum ether and ethanol extracts, showed zone of inhibition against all the three species of Aspergillus with highest zone of inhibition for A. fumigatus $(12.0 \mathrm{~mm})$. MIC values for most of the extracts ranged from 0.75 to $3.0 \mathrm{mg} / \mathrm{mL}$; while the least MFC value was observed at $6.0 \mathrm{mg} / \mathrm{mL}$. Result of MFC showed that at concentration $6.0 \mathrm{mg} / \mathrm{mL}, 75 \%$ of the test Candida species were killed while rests $25 \%$ were inhibited at same concentration. Phytochemical analysis exhibited the presence of alkaloids, flavonoids, carbohydrates, glycosides, protein and amino acids, saponins and triterpenoids in different extracts. These results reveal the antifungal activity of $C$. fistula leaves extracts which may be useful in treatment of candidiasis and aspergillosis. However, further studies with purified fractions or bioactive compounds responsible for antifungal activity need to be evaluated.
\end{abstract}

Keywords: Similipal Biosphere Reserve, candidiasis, aspergillosis, Cassia fistula L.

\section{INTRODUCTION}

The advent of the AIDS in India has brought in its wake a dramatic increase in the impact of life-threatening fungal infections in the immuno-compromised patients. Candida albicans is reported to be the commonest species of Candida causing infection in HIV patients, other species like C. tropicalis, C. glabrata, C. parapsilosis, and C. krusei are also reported (Kumar et al., 1996; Chander, 2002). High degrees of antifungal drug resistance have been reported in Candida species and these have exhibited primary resistance patterns towards nystatin, clotrimazole, fluconazole, itraconazole and amphotericin B (Goff et al., 1995; Nolte et al., 1997). Either nystatin suspension or the clotrimazole douches is the drug of choice in candidiasis for nonimmunosuppressed adults. Patients with advanced HIV infection or other immunosuppressed disorders may not respond to clotrimazole and may require systemic therapy with ketoconazole. Thus there is an exigent need for novel antifungal remedies, and higher plants remain a vital source of these new substances, especially in low resource countries (Iwu and Wootton, 2002). Other fungal infections seen in HIV-infected individuals include aspergillosis due to Aspergillus flavus, $A$. fumigatus and $A$. niger (Musial et al., 1988; Marty and Mylonakis, 2002).

The Similipal massif lies between $21^{\circ} 28^{\prime}$ and $22^{\circ} 08^{\prime}$ North latitude and $86^{\circ} 04^{\prime}$ and $86^{\circ} 37^{\prime}$ East longitude in the Mayurbhanj district of Orissa covering $5,569 \mathrm{~km}^{2}$ of forest land, a unique habitat of mixed tropical forest which harbor varied flora and fauna. The ecosystem is enriched with variety of medicinal plants. The total number of species comprising the flora of the hills is 990, representing 145 families of vascular plants, with occurrence of more than 500 medicinal plants (Saxena and Brahmam 1989; Pandey and Rout, 2002). However, very limited studies on medicinal plants in general and antimicrobial activity of phytochemicals from Similipal Biosphere Reserve have been done (Thatoi et al., 2008; Panda et al., 2009; Rath et al., 2009).

The genus Cassia, comprising 600 species widely distributed world wide and is well known for its diverse biological and pharmacological properties. Cassia fistula L. belongs to Caesalpiniaceae family is widely used for its medicinal properties. In the Indian literature, this plant has been described to be useful against skin diseases, liver troubles, tuberculosis and its use in the treatment of rheumatism, haematemesis, pruritus, leucoderm and diabetes (Alam et al., 1990; Asolkar et al., 1992). This plant is widely used by tribal people to treat various ailments including ringworm and other fungal skin infections (Rajan et al., 2001). The tribes of Similipal externally applied the bark paste of this plant on the bitten area, for 2-3 times a day at regular interval for 3 days. Half teaspoon juice extract is taken orally thrice a day to cure from jaundice. Decoction of mixture containing roots along with equal quantity of roots of Stereospermum chelonoides, latex of Calotropis gigantea and stem juice of 
Musa paradisiaca are mixed with pepper and is given twice a day for 2-3 days for relief from snakebite.

Some studies have also been done on antimicrobial activity of $C$. fistula flower and seed along with some other Indian medicinal plants (Misra et al., 1996; 1997; Valasraj et al., 1997; Perumal Samy et al., 1998; Phongpaichit et al., 2004; Kumar et al., 2006; Duraipandiyan and Ignacimuthu, 2007; Sangetha et al., 2008). These works give little information on antifungal property of this plant. Hence in the present experiment an attempt has been made to evaluate the antifungal activity of different leaf extracts (petroleum ether, chloroform, ethanol, methanol and aqueous) against human pathogenic fungi and the biological activities of the extracts in terms of MIC and MFC were also determined.

\section{MATERIALS AND METHODS}

\section{Plant material}

Bark, fruit and leaves of $C$. fistula $\mathrm{L}$. were collected in the month of April, 2007 from Similipal Biosphere Reserve, Mayurbhanj, Orissa. The collected bark and leaves along with complete herbarium of the plant of $C$. fistula was sent for identification and finally was authenticated by Department of Botany, North Orissa University, Baripada. The shed dried healthy leaves were powdered separately using mechanical grinder and then were passed through sieve so that uniform powder size is maintained.

\section{Preparation of extract}

Sequential extraction was carried out with the same powder $(250 \mathrm{~g})$ using solvents of increasing polarity viz. petroleum ether, chloroform, ethanol, methanol and aqueous solution in Soxhlet apparatus. After about forty siphons of each solvent extraction step, the materials were concentrated by evaporation and stored at $-2{ }^{\circ} \mathrm{C}$ for further study.

\section{Fungi and growth media}

Four species of Candida viz. C. albicans, C. krusei, C. parapsilosis, $C$. tropicalis and three species of Aspergillus viz. A. niger, $A$. fumigatus, $A$. flavus were used as the test organisms and were obtained from SCB Medical College, Cuttack and MTCC, Chandigarh, India (Table 2). These organisms were cultured on Sabouraud dextrose agar at $30{ }^{\circ} \mathrm{C}$ for $24 \mathrm{~h}$ and the stock culture was maintained at 4 ${ }^{\circ} \mathrm{C}$ and subcultured as needed.

\section{Phytochemical analysis}

Preliminary phytochemical study was carried out using method described by Trease and Evans (1989). Each extract was screened for presence of alkaloids, flavonoids, carbohydrates, glycosides, protein and amino acids, tannin and phenolic compounds, saponins, vitamin $\mathrm{C}$, gums and mucilage, triterpenoids, steroid and sterols, fat and fixed oil.

\section{Assay for antifungal activity by agar cup method}

The agar cup method of Barry (1980) was followed with little modification to ensure the antifungal activity of the extracts. Plates of Sabouraud dextrose agar media were seeded with a $100 \mu \mathrm{L}$ of suspension of actively growing over night culture of yeast cells $\left(1.2 \times 10^{6}\right)$. Wells $(6 \mathrm{~mm}$ diameter) were made on Sabouraud dextrose agar plate using a sterile standard cork borer. The bottoms of the wells were sealed by pouring $50-100 \mu \mathrm{L}$ of molten Sabouraud dextrose agar into scooped out wells. A $50 \mu \mathrm{L}$ $(10 \mathrm{mg} / \mathrm{mL})$ of extract were poured into the wells and allowed to dry. The yeast seeded plates were incubated at $31{ }^{\circ} \mathrm{C}$ for $48 \mathrm{~h}$, after which the diameters of zone of inhibitions were measured. For testing against Aspergillus species $0.1 \%$ inoculum suspension were prepared and seeded uniformly on sterile Sabouraud dextrose agar plate and were allowed to dry for $30 \mathrm{~min}$. A test compound of $100 \mu \mathrm{L}(10 \mathrm{mg} / \mathrm{mL})$ was added to the scooped out wells and plates were incubated at $30{ }^{\circ} \mathrm{C}$ for 4 days. Each experiment was carried out in triplicates. The mean zone sizes were taken for evaluating the antifungal activity of the extracts. Those extracts showed good zone of inhibition were further subjected for testing of Minimum Inhibitory Concentration (MIC) and Minimum Fungicidal Concentration (MFC).

\section{Evaluation of MIC and MFC}

A broth micro-dilution technique was adopted using 96 well micro-titer plates and tetrazolium salt (2,3,5Triphenyltetrazolium Chloride) was carried out to determine the MIC by few modification of Eloff (1998) for Candida species. In the plate, $A_{1}$ to $H_{1}$ was the blank and consisted of Sabouraud dextrose broth (SDB) and test organism while $A_{2}$ to $\mathrm{H}_{2}$ consisted of SDB with $20 \mu \mathrm{L}$ of DMSO and test organism. $\mathrm{A}_{3}$ to $\mathrm{H}_{3}$ was the blank and consisted of SDB only. $A_{4}$ to $\mathrm{H}_{4}$ was having the stock solution of the test extract(s) and $A_{5}$ to $H_{5}$ till $A_{12}$ to $H_{12}$ were the wells in which the test extracts were serially diluted using SDB. Wells $A_{12}$ to $D_{12}$ were control having 20 $\mu \mathrm{L}$ of DMSO and $\mathrm{E}_{12}$ to $\mathrm{H}_{12}$ served as control over control. All wells were dispensed with $100 \mu \mathrm{L}$ of SDB. A $20 \mu \mathrm{L}$ of the herbal extract was transferred from stock test solution to the first well i.e. from $\mathrm{A}_{4}$ to $\mathrm{H}_{4}$ containing $100 \mu \mathrm{L}$ of SDB. A $20 \mu \mathrm{L}$ of the SDB containing herbal extract was then transferred to the next well to create serial dilutions. A $100 \mu \mathrm{L}$ of the $0.5 \mathrm{Mc}$ Farland adjusted activated culture in SDB was then added to all the wells except the blank. 5 $\mu \mathrm{L}$ of $0.05 \%$ TTC was further added to all the dilutions, blank, control and control over control. The final volume of all the wells was $205 \mu \mathrm{L}$. The micro-plate was sealed and incubated at $31^{\circ} \mathrm{C}$ at $130 \mathrm{rpm}$ and observed for growth of the Candida species. A $10 \mu \mathrm{L}$ of the broth from each culture tube exhibiting MIC and control tubes were taken aseptically and were plated on one day old SDA plate as a point inoculum and allowed to dry for $10 \mathrm{~min}$ under the laminar air hood to find out MFC. These were then sealed and incubated at $31^{\circ} \mathrm{C}$ for $48 \mathrm{~h}$ and observed for growth of the yeast. 


\section{TLC Bio-autography}

The antifungal activity of the crude and chromatographic fractions was ascertained by bio-autography using agar overlay method (Runyoro et al., 2006). Plant extracts (5 $\mu \mathrm{L}$ ) was applied $2.5 \mathrm{~cm}$ from the base of the silica plate. After drying the plates were developed using solvent chloroform: methanol (8.2:1.8) and chloroform: hexane (5.4:6.6). Overnight culture of $C$. krusei was centrifuged at $3000 \mathrm{rpm}$ for $10 \mathrm{~min}$, resuspended in sterile saline and added to a molten Sabouraud dextrose agar containing $1 \%$ glycerol $(\mathrm{v} / \mathrm{v})$. This overlay was poured on a separate TLC sterilized glass plate in a Petri plate and allowed to solidify under aseptic conditions. The plate was then incubated at $31^{\circ} \mathrm{C}$ for $48 \mathrm{~h}$. The active compounds were shown as white zone over the plates. The $R_{f}$ value of the active compounds was recorded and the zone of inhibition was measured.

Table 1: Screening of phytochemicals of Cassia fistula leaves

\begin{tabular}{|c|c|c|c|c|c|}
\hline Name of the test & $\begin{array}{l}\text { Petroleum } \\
\text { ether extract }\end{array}$ & $\begin{array}{c}\text { Chloroform } \\
\text { extract }\end{array}$ & $\begin{array}{l}\text { Ethanol } \\
\text { extract }\end{array}$ & $\begin{array}{c}\text { Methanol } \\
\text { extract }\end{array}$ & $\begin{array}{c}\text { Aqueous } \\
\text { extract }\end{array}$ \\
\hline Color \& physical appearance & Brownish, hard & Blackish, hard & Blackish, sticky & $\begin{array}{l}\text { Greenish } \\
\text { black, sticky }\end{array}$ & $\begin{array}{c}\text { Greenish } \\
\text { black, sticky }\end{array}$ \\
\hline$\%$ of yield & 2.45 & 1.52 & 15.86 & 4.34 & 6.82 \\
\hline Alkaloids & - & - & + & ++ & ++ \\
\hline Carbohydrates & - & - & - & + & +++ \\
\hline $\begin{array}{l}\text { Tannin and phenolic } \\
\text { compounds }\end{array}$ & +++ & + & ++ & ++ & ++ \\
\hline Glycosides & - & - & + & + & - \\
\hline Protein and amino acids & - & - & + & + & ++ \\
\hline Gum and mucilages & - & - & - & - & - \\
\hline Flavonoids & ++ & ++ & ++ & ++ & ++ \\
\hline Saponins & - & + & + & + & - \\
\hline Steroid and sterols & - & - & - & - & - \\
\hline Triterpenoids & +++ & - & + & + & - \\
\hline Oils and fat & - & - & - & - & - \\
\hline Vitamin C & - & - & - & - & - \\
\hline
\end{tabular}

$(+++)$ Present in high amount; (++) Present in moderate amount; (+) Present in trace amount; (-) Absent

Table 2: List of fungus used to assess the antifungal activity

\begin{tabular}{lllll}
\hline Sl. & \multicolumn{1}{c}{$\begin{array}{c}\text { Name of the } \\
\text { No }\end{array}$} & \multicolumn{1}{c}{ Relevant properties } & Sources \\
\cline { 3 - 4 } & \multicolumn{1}{c}{ Resistant to } & \multicolumn{1}{c}{ Sensitive to } & \\
\hline 1. & Candida albicans & $\mathrm{Ak}, \mathrm{B}, \mathrm{C}, \mathrm{Ce}, \mathrm{E}, \mathrm{G}, \mathrm{Gf}, \mathrm{Nf}$ & $\mathrm{Ap}, \mathrm{Cc}, \mathrm{It}, \mathrm{Kt}, \mathrm{Ns}, \mathrm{Pb}$ & SCB medical College, Cuttack \\
2. & Candida krusei & $\mathrm{Ap}, \mathrm{C}, \mathrm{Cc}, \mathrm{It}, \mathrm{Kt}, \mathrm{Ns}$ & $\mathrm{Ak}, \mathrm{B}, \mathrm{Ce}, \mathrm{E}, \mathrm{G}, \mathrm{Gf}, \mathrm{Nf}, \mathrm{Pb}$ & SCB medical College, Cuttack \\
3. & Candida parapsilosis & $\mathrm{Ak}, \mathrm{B}, \mathrm{C}, \mathrm{Ce}, \mathrm{E}, \mathrm{G}, \mathrm{Gf}, \mathrm{Nf}$ & $\mathrm{Ap}, \mathrm{Cc}, \mathrm{It}, \mathrm{Kt}, \mathrm{Ns}, \mathrm{Pb}$ & SCB medical College, Cuttack \\
4. & Candida tropicalis & $\mathrm{Ak}, \mathrm{B}, \mathrm{C}, \mathrm{Ce}, \mathrm{E}, \mathrm{G}, \mathrm{Gf}, \mathrm{It}, \mathrm{Nf}$ & $\mathrm{Ap}, \mathrm{Cc}, \mathrm{Kt}, \mathrm{Ns}, \mathrm{Pb}$ & SCB medical College, Cuttack \\
5. & Aspergillus flavus & $\mathrm{Ak}, \mathrm{Ap}, \mathrm{B}, \mathrm{Cc}, \mathrm{Ns}$ & $\mathrm{Ap}, \mathrm{Cc}, \mathrm{It}, \mathrm{Kt}, \mathrm{Nf}$ & SCB medical College, Cuttack \\
6. & A. fumigatus & $\mathrm{Ak}, \mathrm{Ap}, \mathrm{B}, \mathrm{Cc}, \mathrm{It}, \mathrm{Ns}$ & $\mathrm{Ap}, \mathrm{Cc}, \mathrm{It}, \mathrm{Kt}, \mathrm{Nf}$ & SCB medical College, Cuttack \\
7. & A. niger & $\mathrm{Ak}, \mathrm{Ap}, \mathrm{B}, \mathrm{Cc}, \mathrm{Kt}, \mathrm{Ns}$ & $\mathrm{Cc}, \mathrm{It}, \mathrm{Nf}, \mathrm{Pb}$ & $\mathrm{MTCC}$ 871, Chandigarh \\
\hline
\end{tabular}

Amikacin-Ak (30 $\mu \mathrm{g})$; Amphotericin B-Ap (100 unit); Bacitracin-B (10 units); Cephotaxime-Ce (30 $\mu \mathrm{g})$; Ciprofloxacin-C (10 $\mu \mathrm{g})$; Clotrimazole-Cc $(10 \mu \mathrm{g})$; Erythromycin-E $(15 \mu \mathrm{g})$; Gentamycin-G $(10 \mu \mathrm{g})$; Gatifloxacin-Gf (30 $\mu \mathrm{g})$; Itraconozole-It $(10 \mu \mathrm{g})$; Ketoconazole-Kt $(10 \mu \mathrm{g})$; Nitrofurantoin-Nf $(300 \mu \mathrm{g})$; Nystatin- Ns $(100 \mu \mathrm{g})$; Polymyxin B-Pb (300 unit) 
Table 3: Screening of antifungal activity of Cassia fistula leaves by agar cup method

\begin{tabular}{lllllll}
\hline Name of the strain & \multicolumn{5}{c}{ Zone of inhibitions in $\mathbf{~ m m}$} \\
\cline { 2 - 7 } & $\begin{array}{c}\text { Petroleum } \\
\text { ether }\end{array}$ & Chloroform & Ethanol & Methanol & Aqueous & Clotrimazole \\
\hline Candida albicans & $12.6 \pm 0.5$ & $10.0 \pm 2.0$ & $12.0 \pm 1.0$ & $10.6 \pm 1.5$ & $11.6 \pm 0.5$ & $20.0 \pm 1.0$ \\
Candida krusei & $11.0 \pm 1.0$ & - & $13.3 \pm 1.1$ & $12.3 \pm 0.5$ & $13.0 \pm 1.0$ & $14.33 \pm 0.5^{*}$ \\
Candida parapsilosis & $12.6 \pm 1.1$ & - & $12.3 \pm 0.5$ & $12.6 \pm 1.1$ & $14.0 \pm 1.0$ & $28.6 \pm 1.1$ \\
Candida tropicalis & $12.0 \pm 0.0$ & - & $14.3 \pm 0.5$ & $10.0 \pm 0.0$ & $12.3 \pm 0.5$ & $29.6 \pm 1.1$ \\
Aspergillus flavus & $11.6 \pm 0.7$ & - & $9.6 \pm 0.70$ & $12.3 \pm 0.7$ & - & $14.3 \pm 0.7$ \\
Aspergillus fumigatus & $12.0 \pm 0.0$ & - & $12.0 \pm 2.12$ & - & $10.6 \pm 1.4$ & $15.6 \pm 1.4$ \\
Aspergillus niger & $11.6 \pm 0.7$ & $9.0 \pm 0.0$ & $10.6 \pm 1.6$ & $10.6 \pm 0.57$ & $11.6 \pm 0.57$ & $18.3 \pm 2.8$ \\
\hline
\end{tabular}

(Zone of inhibition of mean \pm SD in $\mathrm{mm}$ ); (-) No zone of inhibition; Zone of inhibition including $6 \mathrm{~mm}$ borer; ${ }^{*}$ Cephotaxime

Preliminary screening of antifungal activity was evaluated using agar cup method against seven isolates are shown in Table 3 . It is noteworthy that most of the extracts produced no measurable activity against $A$. niger, $A$. flavus and $A$. fumigatus (except methanol and ethanol extracts showed zone of inhibition $>12.0 \mathrm{~mm}$ ). Also the chloroform extract did not show any activity against test strains. Consequently chloroform extract and Aspergillus species were removed from next experiment. The result of antifungal activity shown that there was no significant difference among the Candida species, while there were marked differences between the activities of the plant extracts and those of the pure antifungal drugs (Table 3). Such significant differences are normally present when crude (unpurified) plant extracts are compared with pure drugs that are already in clinical use (Yoder, 1982). Also the agar cup method is not always dependable for accurate assessment and comparison. This is because of the high degree of interference inherent in this method, arising from drug diffusion problems (Dickert et al., 1981). In the second stage ethanol, methanol, aqueous and petroleum ether extracts were used for finding of MIC and MFC.

A more generally accurate method of assessment is the broth dilution technique. In this study, therefore, the broth dilution method was used in determining the activities measured as MIC. In using this method, higher degrees of differences in susceptibility among Candida species were observed (Table 4). It would appear that $C$. krusei is the most sensitive yeast to all test extracts. $C$. krusei is one of the non-albicans Candida strains currently emerging in fungal infections (Samaranayake and Samaranayake, 1994). The effect of the unrefined nature of the plant extracts as compared to the reference drugs is once more apparent. But there is obvious evidence that the plant extracts has a substantial level of antifungal activity. The result of MIC showed that $31.25 \%$ of extracts were active in a concentration $750 \mu \mathrm{g} / \mathrm{mL}$ and $87.5 \%$ of extracts were active in a concentration of $1500 \mu \mathrm{g} / \mathrm{mL}$ (Table 4). However at concentration $3000 \mu \mathrm{g} / \mathrm{mL}, 100 \%$ of inhibition was recorded. Result of MFC showed that at concentration $6.0 \mathrm{mg} / \mathrm{mL}, 75 \%$ of the tested Candida strains were killed while rest $25 \%$ was inhibited at same concentration. TLC using chloroform: methanol (8.2:1.8) as the developing solvent was able to separate ethanol extract into 5 distinct fractions with retention factor $\left(R_{f}\right)$ value $0.72,0.55,0.43,0.37$ and 0.09 . All the fractions of ethanol extract were tested against $C$. krusei to determine antifungal activity and result obtained that antifungal activity was limited to fraction with $R_{f} 0.72$, which was evident as a bluish pink colour under exposure to UV light on the references TLC plate with zone of inhibition higher than $20 \mathrm{~mm}$. With uncommon exceptions, all the polar extracts had better antifungal activity probably due to better solubility in ethanol, methanol and water of the active constituents responsible for the pharmacological activity.

Table 4: Screening of antifungal activity by Minimum Inhibitory Concentration and Minimum Fungicidal Concentration

\begin{tabular}{lcccccccccc}
\hline \multirow{2}{*}{ Name of the strain } & \multicolumn{2}{c}{$\begin{array}{c}\text { Petroleum } \\
\text { ether }\end{array}$} & \multicolumn{2}{c}{ Ethanol } & \multicolumn{2}{c}{ Methanol } & \multicolumn{3}{c}{ Aqueous } & \multicolumn{2}{c}{ Clotrimazole } \\
& MIC & MFC & MIC & MFC & MIC & MFC & MIC & MFC & MIC & MFC \\
\hline Candida albicans & 1.5 & 6.0 & 0.75 & 6.0 & 1.5 & 6.0 & 3.0 & 6.0 & 0.002 & 0.002 \\
Candida krusei & 1.5 & 6.0 & 0.75 & 6.0 & 0.75 & 6.0 & 0.75 & 6.0 & $0.001^{*}$ & $0.001^{*}$ \\
Candida parapsilosis & 1.5 & 6.0 & 0.75 & 6.0 & 1.5 & 6.0 & 1.5 & 6.0 & 0.002 & 0.002 \\
Candida tropicalis & 3.0 & 6.0 & 1.50 & $<6.0$ & 1.5 & $<6.0$ & 1.5 & $<6.0$ & 0.002 & 0.004 \\
\hline
\end{tabular}

\footnotetext{
${ }^{*}$ Cephotaxime
} 


\section{DISCUSSION}

Frequently Candida infection has risen dramatically since the advent of antibiotics and development of the drug resistant. Development of drug resistant pathogens demand new strategies and the native peoples ethnobotanical knowledge has received less emphasis and is a valuable resource which should be utilized to advance health oriented objectives. Since the incidence of Candida strains with multiple antibiotic resistances is increasing world wide, it is of great importance to find effective treatments for infection of these pathogens. Novel, safe and effective compounds may be found through consultation with traditional healers or tribal peoples using herbal medicines. Certainly indigenous plants are reservoirs of novel antimicrobials; they would play important roles in providing us with such bioactive in future. This encouraged us to evaluate the natural resources of our country to identify an antifungal agent, particularly against $C$. albicans, $C$. tropicalis, $C$. parapsilosis, C. krusei, A. niger, $A$. flavus and $A$. fumigatus.

Oral candidiasis is usually treated by topical antifungal agents, which include nystatin, clotrimazole, fluconazole, itraconazole and amphotericin B (Goff et al., 1995; Nolte et al., 1997). However, these antibiotics are getting resistance to Candida species (Perea et al., 2001). The organism used in our experiments such as $C$. krusei, $C$. tropicalis, A. niger, $A$. fumigatus, $A$. flavus are resistant to nystatin, clotrimazole, itraconazole and amphotericin $B$ (Table 2). The susceptibilities of the different fungus to both the plant extracts and standard antifungal agents were determined by the agar cup method. The zone of inhibitions was obtained as maximum for ethanol extract followed by methanol and aqueous extracts. Among the yeast strains $C$. tropicalis is most sensitive showed highest zone of inhibition $(14.3 \mathrm{~mm})$ followed by $C$. parapsilosis $(14.0 \mathrm{~mm})$ and $C$. krusei (13.0). Candida albicans showed least zone of inhibition against all the test extracts (highest zone of inhibition $12.6 \mathrm{~mm}$ ). Among Aspergillus, petroleum ether and ethanol extracts showed zone of inhibition against all the three species with highest zone of inhibition for $A$. fumigatus $(12 \mathrm{~mm})$. However, chloroform extract does not showed any activity against any one of the Aspergillus species while, petroleum ether and aqueous extract showed least activity against $A$. flavus.

At the preliminary stage of the study, it is yet not clear which of the phytochemical constituents is dominantly responsible for the antifungal activity. A polar compounds including 5-nontetra contanone, 2-hentriacontanone, triacontane, 16-hentriacontanol and sitosterol along with oil showing antibacterial activity have also been isolated in C. fistula pods (Misra et al., 1996). Fistucacidin, an optically inactive leuco-anthocyanidin (3,4,7,8,4' pentahydroxyflavan) was first extracted from the heartwood (Rao and Venkateswarlu, 1965). Kaempferol and a proanthocyanidin have been isolated from the acetone extract of the flower (Narayanan and Seshadri, 1972). Morimoto et al. (1988) isolated (-)epiafzelechin 3-
O- $\beta$-D-glucopyranoside, 7 biflavonoids and two triflavonoids together with (-)epiafzelechin, (-)epicatechin and procyanidin B-2 from the leaves. A bianthraquinone glycoside, fistulin together with kaempferol and rhein have been isolated from ethanol extracts of Cassia fistula flowers (Kumar et al., 1966). Besides phenolics and their derivatives, a certain amount of alkaloids have also been reported in the flowers (Asseleih et al., 1990); traces of triterpenes have been observed in both flowers and fruits (Guri-Fakim et al., 1994). A compound, 3- $\beta$-hydroxy-17norpimar-8(9)-en-15-one was isolated from the pods of Cassia fistula (Misra et al., 1996). But there is no evidence that the antifungal action resides in this compound. However, a first approximation, based on other literature reports, may be to attribute this activity to presence of phytochemicals such as flavonoids, glycosides, tannin and phenolic compounds and triterpenoids. Rauha et al. (2000) investigated that the presence of phenolic compounds in Finnish plant extracts and are effective in inhibiting the growth of the organism's particularly $C$. albicans. Phenolic compounds like tannins, found in plant cells are potent inhibitors of hydrolytic enzymes used by plant pathogens (Rath et al., 2009). Favel et al. (2005) isolated steroidal glycosides named alexin from crude extract of Yucca gloriosa L. and investigated in vitro antifungal activity against a panel of human pathogenic fungi, yeast as well as dermatophytes and filamentous species. A lot of scientific work narrates that many plants and their isolates containing terpenoids, possess antifungal activity. Ankri and Mirelman (1999) showed antimicrobial properties of allicin from garlic particularly antifungal activity against $C$. albicans. Hence, presence of these phytochemicals in polar extracts such as ethanol, methanol and aqueous extracts may be responsible for antifungal activity against all tested strain, which need further investigation.

Valasraj et al. (1997) studied antibacterial activity of C. fistula seeds by broth dilution method and antifungal activity by agar cup method. According to them no zone of inhibition was found against $A$. niger. PerumalSamy et al. (1998) have reported that $C$. fistula leaves extracts showed antibacterial activity against a wide spectrum of bacteria such as Escherichia coli, Klebsiella aerogenes, Pseudomonas aeruginosa and Proteus vulgaris. Similarly Phongpaichit et al. (2004) reported that the methanol extract from the leaves of $C$. fistula had $100 \%$ antifungal activity at $10 \mathrm{mg} / \mathrm{mL}$ against Trichophyton rubrum, Microsporum gypseum and Penicillium marneffei. Kumar et al. (2006) found antimicrobial activity of fruit of $C$. fistula by agar dilution streak method at a concentration 500 $\mu \mathrm{g} / \mathrm{mL}$. Only $E$. coli and $P$. aeruginosa, were moderately inhibited where as no inhibition were found in case of Bacillus subtilis, $S$. epidermidis and $A$. niger. Duraipandiyan and Ignacimuthu (2007) studied antimicrobial activity of five extracts (hexane, chloroform, ethyl acetate, methanol and water) of $C$. fistula flowers along with a isolated compound 4-hydroxybenzoic acid hydrate against both fungi and bacteria. They conclude that $C$. albicans was not inhibited by any of the tested extracts. However, A. niger was inhibited by all extracts 
with MIC value $>1 \mathrm{mg} / \mathrm{mL}$ for all the tested extract. Sangetha et al. (2008) tested C. fistula extracts of leaves, flowers, stem and pod with $C$. albicans and $A$. niger along with other fungi and bacteria. They reported that $A$. niger was susceptible to all extracts except the extract of $C$. fistula pod, while $C$. albicans was susceptible to all extract of $C$. fistula. Antimicrobial activity of $C$. fistula leaves, stem bark, and pods was carried out against 14 pathogenic bacteria and 6 fungi at $400 \mathrm{~g} /$ disc (Abbas et al., 2004). Our report is the first for antifungal activity.

So far antibacterial activity tested by Valasraj et al. (1997); Kumar et al. (2006) and PerumalSamy et al. (1998) on seeds of $C$. fistula, no work has been done from leaves. Studies made by these workers indicate that seed extracts exhibits potential significant antibacterial activity and can replace some of the conventional antibiotics, thus giving an alternative for the treatment of infectious diseases. In the present investigation we have placed in record that the antimicrobial activity of $C$. fistula leaves from Simlipal Biosphere Reserve against different human pathogenic fungi. Comparison of the data obtained in this study with previously published result is problematic. First, the composition of the plant extracts is known to vary according to local climatic and environmental conditions (Janssen et al., 1987; Sivropoulou et al., 1995). Secondly the method used to assess antimicrobial activity and the choice of the test organisms also varies (Janssen et al., 1987). Most frequently used methods to antibacterial activity are agar diffusion techniques and broth dilution methods. The results obtained by each of these methods may differ as many factors vary between assays (Janssen et al., 1987). In vivo studies may be required to confirm the values of the some of the results obtained.

Active compound(s) may be present in insufficient quantities in the crude extracts to show activity with the dose levels employed. Lack of activity can thus only be proven by using large doses. On the other hand, if the active principle is present in high quantities, there could be other constituents exerting antagonistic effects of the bioactive compounds. However, to know the exact mechanism of action of $C$. fistula extracts, further studies with purified fractions or bioactive compounds are necessary.

\section{ACKNOWLEDGEMENTS}

The present research has been funded by the Department of Science and Technology, Government of Orissa (Grant No. 2818/28.6.2006). We are also grateful to the authorities of North Orissa University for providing necessary facilities to carry out this research.

\section{REFERENCES}

Abbas, A. M., Sayeed, A. M., Bhuiyan, M. S. A., Sohel, F. I. and Yeasmin, S. M. S. T. (2004). Antimicrobial screening of Cassia fistula and Mesua ferrea. Journal of Medical Science 4, 24-29.
Alam, M. M., Siddiqui, M. B. and Hussian, W. (1990). Treatment of diabetes through herbal drugs in rural India. Fitoterapia 61, 240-242.

Ankri, S. and Mirelman, D. (1999). Antimicrobial properties of allicin from garlic. Microbes and Infection 1, 125-129.

Asolkar, L. V., Kakkar, K. K. and Chakre, O. J. (1992). Second supplement to glossary of Indian medicinal plant with active principles. Publication and Information Directorate, CSIR, New Delhi. pp. 1-177.

Asseleih, L. M. C., Hernandez, O. H. and Sanchez, J. R. (1990). Seasonal variation in the content of sennosides in leaves and pods of two Cassia fistula populations. Phytochemistry 29, 3095-3099.

Barry, A. L. (1980). Procedure for testing antimicrobial Agents in Agar media. In: Antibiotics in Laboratory Medicine. Lorin V (eds.). Williams Wilkins Co., Baltimore. pp. 1-23.

Chander, J. (2002). Textbook of Medical Mycology. $2^{\text {nd }}$ edn. Mehta Puublishers, New Delhi. pp. 216-226.

Dickert, H., Machka, K. and Braveny, I. (1981). The uses and limitations of disc diffusion in the antibiotic sensitivity testing of bacteria. Infection 9, 18-24.

Duraipandiyan, V. and Ignacimuthu, S. (2007). Antibacterial and antifungal activity of Cassia fistula L.: An ethnomedicinal plant. Journal of Ethnopharmacology 112, 590-594.

Eloff, J. N. (1998). A sensitive and quick microplate method to determine the minimum inhibitory concentration of plant extracts for bacteria. Planta Medica 64, 711-713.

Favel, A., Kemertelidze, E., Benidze, M., Fallague, K. and Regli, P. (2005). Antifungal Activity of Steroidal Glycosides from Yucca gloriosa L. Phytotherapy Research 19, 158-161.

Goff, D. A., Koletar, S. L., Buesching, W. J., Barnishan, J. and Fass, R. J. (1995). Isolation of flucanozole-resistant Candida albicans from HIVnegative patients never treated with azoles. Clincal Infectious Disease 20, 77-83.

Guri-Fakim, A., Gueho, J., Sewraj, M.D. and Dulloo, E. (1994). Plantes Medicinales de lile Maurice. Editions de L'Ocean Indien, Mauritius, pp. $\mathbf{5 8 0 .}$

Iwu, M. M. and Wootton, J. (2002). Advances in Phytomedicine Vol. 1, Ethnomedicine and Drug Discovery, Elsevier, Amsterdam. pp. 6-26.

Janssen, A. M., Scheffer, J. J. C. and BaerheimSvendsen, A. (1987). Antimicrobial activity of essential oils: a 1976-86 literature review. Aspects of the test methods. Planta Medica 53, 395-398.

Kumar, A., Pande, C.S. and Kaul, R.K. (1966). Chemical examination of Cassia fistula flowers. Indian Journal of Chemistry 4, 460.

Kumar, B., Rajagopalan, M. and Sehgal, S. (1996). Candidal esophagitis- a marker for HIV infection. Indian Journal Dermatology Venerology Leprology 56, 230-231.

Kumar, V. P., Chau, N. S., Padhi, H. and Rajani, M. (2006). Search for antibacterial and antifungal agents 
from selected Indian medicinal plants. Journal of Ethnopharmacology 67, 241-245.

Marty, F. and Mylonakis, E. (2002). Antifungal use in HIV infection. Expert Opinion Pharmacotherapy 3, 91-102.

Misra, T. R., Singh, R. S., Pandey, H. S. and Pandev, R. P. (1996). Chemical constituents of hexane fraction of Cassia fistula pods. Fitoterapia 57, 173174.

Misra, T. R., Singh, R. S., Pandey, H. S. and Singh, B. K. (1997). A new diterpene from Cassia fistula pods. Fitoterapia 58, 375-377.

Morimoto, S., Nonaka, G. and Chen, R. (1988) Tannins and related compounds. LXI. Isolation and structures of novel bi-and triflavonoids from the leaves of Cassia fistula L. Chemical Pharmacology Bulletin 36, 39-47.

Musial, C. E., Cockenii, F. R., Roberts, G. D. (1988). Fungal infections of the immunocompromised host. Clinical laboratory aspects. Clinical Microbiology Review 1, 349-364.

Narayanan, V. and Seshadri, T. R. (1972). Proanthocyanidins of Cassia fistula. Indian Journal of Chemistry 10, 379-381.

Nolte, F. S., Parkinson, T. and Falconer, D. J. (1997). Isolation and charecterisation of flucanazole and amphoterecin B resistant Candida albicans from blood of two patients with leukemia. Antimicrobial Agents Chemotherapy 41, 196-199.

Panda, S. K., Thatoi, H. N. and Dutta, S. K. (2009). Antibacterial activity and phytochemical screening of leaves and bark extracts of Vitex negundo L. from Similipal Biosphere Reserve, Orissa. Journal of Medicinal Plant Research 3, 294-300.

Pandey, A. K. and Rout, S. D. (2002). Medicinal Plants of Similipal Biosphere Reserve. In: Perspectives of Plant Biodiversity. Das, A. P. (ed.). Bishen Singh Mahendra Pal Singh, Dehra Dun. pp. 681-696.

Perea, S., Lopez-Ribot, J. L., Kirkpatrick, W. R., McAtee, R. K., Santillan, R. A., Martínez, M., Calabrese, D., Sanglard, D. and Patterson, T. F. (2001). Prevalence of molecular mechanisms of resistance to azole antifungal agents in Candida albicans strains, displaying high-level fluconazole resistance isolated from human immunodeficiency virus-infected patients. Antimicrobial Agents Chemotherapy 45, 2676-2684.

PerumalSamy, R. S., Iggnacimuthu, S. and Sen, A. (1998). Screening of 34 medicinal plants antibacterial properties. Journal of Ethnopharm-acology 62, 173182.

Phongpaichit, S., Pujenjob, N., Rukachaisirkul, V. and Ongsakul, M. (2004). Antifungal activity from leaves extracts of Cassia alata L., Cassia fistula L. and Cassia tora L. Songklanakarin Journal of Science and Technology 26, 741-748.

Rajan, S., Baburaj, D. S., Sethuraman, M. and Parimala, S. (2001). Stem and stem bark used medicinally by the Tribals Irulas and Paniyas of Nilgiri District, Tamilnadu. Ethnobotany 6, 19-24.
Rao, T. V. P. and Venkateswarlu, V. (1965). "Fistucacidin" from the bark and heartwood of Cassia fistula Linn. Bulletin of National Institute of Sciences of India 31, 28-33.

Rath, S. K., Mohapatra, N., Dubey, D., Panda, S. K., Thatoi, H. N. and Dutta, S. K. (2009). Antimicrobial activity of Diospyros melanoxylon bark from Similipal Biosphere Reserve, Orissa, India. African Journal of Biotechnology 8, 1924-1928.

Rauha, J. P., Remes, S., Heinonen, M., Hopia, A., Kahkonen, M., Kujala, T., Pihlaja, K., Vuorela, H. and Vuorela, P. (2000). Antimicrobial effects of Finnish plant extracts containing flavonoids and other phenolic compounds. International Journal of Food Microbiology 56, 3-12.

Runyoro D. K., Matee, M. I., Ngassapa, O. D., Joseph, C. C., Mbwambo, Z. H. (2006). Screening of Tanzanian medicinal plants for anticandidal activity. $B M C$ complementary and alternative medicine 6, 1121.

Samaranayake, Y. H. and Samaranayake, L. P. (1994). Candida krusei: biology, epidemiology, pathogenecity and clinical manifestations of an emerging pathogen. Journal Medical Microbiology 41, 295-310.

Sangetha, S. N., Zuraini, Z., Sasidharan, S. and Suryani, S. (2008). Antimicrobial activities of Cassia surattensis and Cassia fistula. Journal of Molecular Biology and Biotechnology 1, 1-4.

Saxena, H. O. and Brahmam, M. (1989). The flora of Similipahar (Similipal), Orissa. Regional Research Labarotory, Bhubaneswar. pp. 1-231.

Sivropoulou, A., Kokkini, S., Lanaras, T. and Arsenakis, M. (1995). Antimicrobial activity of mint essential oils. Journal Agriculture Food Chemistry 43, 2384-2388.

Thatoi, H. N., Panda, S. K., Rath, S. K. and Dutta, S. K. (2008). Antimicrobial activity and ethnomedi-cinal uses of some medicinal plants from Similipal Biosphere Reserve, Orissa. Asian Journal of Plant Science 7, 260-267.

Trease, G. E. and Evans, W. C. (1989). Text book of Pharmocognosy. $13^{\text {th }}$ edn. Alden Press. Oxford. pp. 268-298.

Valsaraj, R., Pushpangadan, P., Smitt, U. W., Adersen, A. and Nyman, U. (1997). Antimicrobial screening of selected medicinal plants from India. Journal of Ethnopharmacology 58, 75-83.

Yoder, S. (1982). Biomedical and ethnomedical practices in rural Zaire: Contrasts and complements. Social Science and Medicine 16, 1851-1857. 